PREPARED FOR THE U.S. DEPARTMENT OF ENERGY, UNDER CONTRACT DE-AC02-76CH03073

PPPL-3944

PPPL-3944

UC-70

Fast Neutral Pressure Gauges in NSTX

by

R. Raman, H.W. Kugel, R. Gernhardt. T. Provost,

T.R. Jarboe, and V. Soukhanovskii

April 2004

NM|

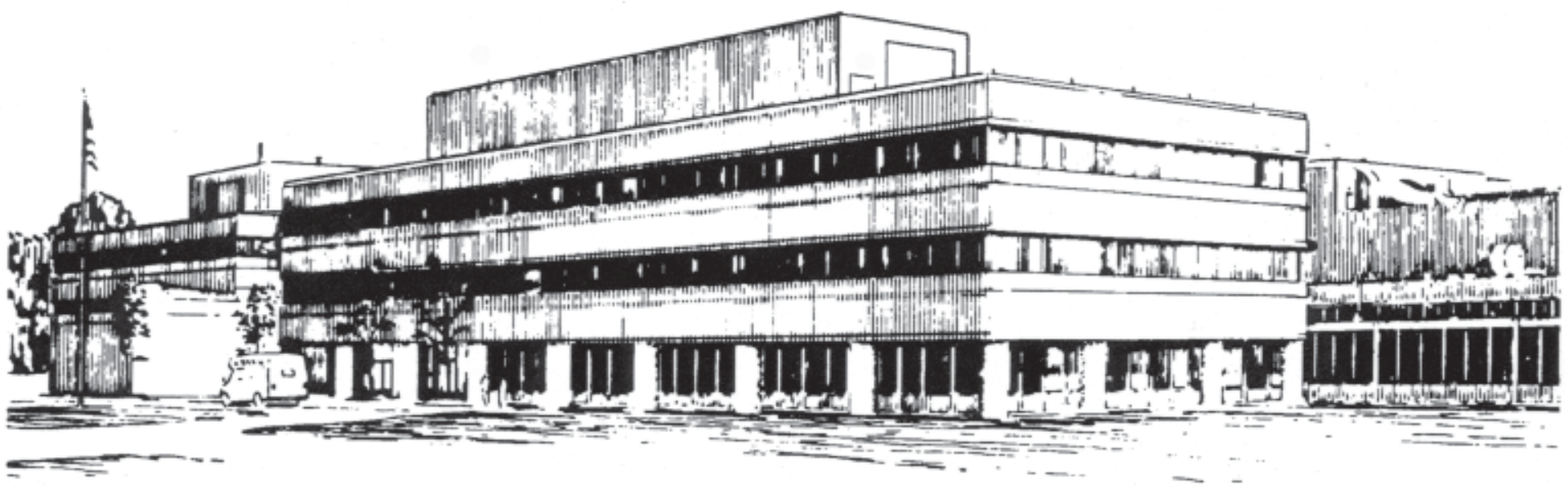

PRINCETON PLASMA PHYSICS LABORATORY PRINCETON UNIVERSITY, PRINCETON, NEW JERSEY 


\section{PPPL Reports Disclaimer}

This report was prepared as an account of work sponsored by an agency of the United States Government. Neither the United States Government nor any agency thereof, nor any of their employees, makes any warranty, express or implied, or assumes any legal liability or responsibility for the accuracy, completeness, or usefulness of any information, apparatus, product, or process disclosed, or represents that its use would not infringe privately owned rights. Reference herein to any specific commercial product, process, or service by trade name, trademark, manufacturer, or otherwise, does not necessarily constitute or imply its endorsement, recommendation, or favoring by the United States Government or any agency thereof. The views and opinions of authors expressed herein do not necessarily state or reflect those of the United States Government or any agency thereof.

\section{Availability}

This report is posted on the U.S. Department of Energy's Princeton Plasma Physics Laboratory Publications and Reports web site in Fiscal Year 2004. The home page for PPPL Reports and Publications is: http://www.pppl.gov/pub_report/

DOE and DOE Contractors can obtain copies of this report from:

U.S. Department of Energy

Office of Scientific and Technical Information

DOE Technical Information Services (DTIS)

P.O. Box 62

Oak Ridge, TN 37831

Telephone: (865) 576-8401

Fax: (865) 576-5728

Email: reports@adonis.osti.gov

This report is available to the general public from:

National Technical Information Service

U.S. Department of Commerce

5285 Port Royal Road

Springfield, VA 22161

Telephone: $1-800-553-6847$ or

(703) $605-6000$

Fax: (703) 321-8547

Internet: http://www.ntis.gov/ordering.htm 


\title{
Fast Neutral Pressure Gauges in NSTX
}

\author{
${ }^{1}$ R. Raman, ${ }^{2}$ H.W. Kugel, ${ }^{2}$ R.Gernhardt, ${ }^{2}$ T. Provost, ${ }^{1}$ T.R. Jarboe, V. Soukhanovskii ${ }^{3}$ \\ ${ }^{1}$ University of Washington, Seattle, WA \\ ${ }^{2}$ Princeton Plasma Physics Laboratory, Princeton, NJ \\ ${ }^{3}$ Lawrence Livermore National Laboratory, Livermore, $C A$
}

\begin{abstract}
Successful operation in NSTX of two prototype fast-response micro ionization gauges during plasma operations has motivated us to install five gauges at different toroidal and poloidal locations to measure the edge neutral pressure and its dependence on the type of discharge (L-mode, H-mode, CHI) and the fuelling method and location. The edge neutral pressure is also used as an input to the transport analysis codes TRANSP and DEGAS-2. The modified PDX-type Penning gauges are well suited for pressure measurements in the NSTX divertor where the toroidal field is relatively high. Behind the NSTX outer divertor plates where the field is lower, an unshielded fast ion gauge of a new design has been installed. This gauge was developed after laboratory testing of several different designs in a vacuum chamber with applied magnetic fields.
\end{abstract}

\section{Introduction}

The National Spherical Torus Experiment [1] (NSTX) is designed to explore the physics of low toroidal aspect-ratio plasmas combining high beta and high confinement simultaneously. NSTX has a major radius of $0.85 \mathrm{~m}$, minor radius of $0.68 \mathrm{~m}$ and plasma elongation up to 2.5. The nominal range in toroidal field is 0.3 to $0.6 \mathrm{~T}$ and the plasma current up to $1.5 \mathrm{MA}$. The device is fueled using gas injection from piezo valves at four different locations on the machine, from two locations on the center stack and, during CHI operations [2], from the lower divertor plate region. Neutral pressure gauges are needed for basic plasma operations and as in input parameter for transport codes such as DEGAS-2 and TRANSP. Neutral pressure measurements will also facilitate analysis of divertor pumping requirements. Because NSTX operates with several novel gas injection sources while exploring numerous plasma configurations, an understanding of neutral 
pressure behavior at different locations in the machine is needed. Eventually these measurements are also needed for future machines such as ITER. Because fast time scale measurements require the gauge to be present very close to the plasma boundary, fast neutral pressure measurements - especially to establish edge neutral pressures is non trivial as most gauges do not operate under conditions of strong magnetic fields. Because different types of gauges are suited for specific applications we are investigating the use of three different types of gauges for the purpose of exploring the operating range and capability of these gauges. These are shielded ion gauges, Penning gauges and unshielded ion gauges. These are described in the subsequent sections.

\section{The Penning Gauges}

Modified, PDX-type Penning gauges [3,4] were installed on the upper and lower divertors of NSTX. These gauges have a cylindrical anode measuring $1.27 \mathrm{~cm}$ in diameter and $1.26 \mathrm{~cm}$ long. $2.6 \mathrm{~cm}^{2}$ steel plates separated from the cylinder ends by $2.6 \mathrm{~mm}$, act as the cathode. Voltages in the range of 2 to $5 \mathrm{kV}$ were used for experimentation. A voltage of $3.12 \mathrm{kV}$ was selected in the final configuration. This increases the maximum operating range for the pressure while ensuring that the Penning discharge initiates at the lower pressures. Since installing them more than two years ago, these gauges have required no maintenance. The calibration data, as shown in Figure 1, at a toroidal field of $0.45 \mathrm{~T}$ at the machine axis shows the calibration to have remained essentially unchanged over the past two years [5] even though NSTX has gone through several machine bake-out cycles at $300^{\circ}$ Celsius and numerous boronization and He glow discharge cycles. These gauges are not isolated from the machine during these machine conditioning events. These factors as well as their capability to operate at high values of the toroidal field, and retain their calibration over long periods may make them better suited for harsh environments such as that which may exist in ITER. On NSTX, these gauges have a maximum operating pressure of up to $1 \mathrm{~m}$ Torr although by reducing the bias voltage this could be extended up to about $4 \mathrm{mT}$ Torr.

\section{The Micro Ion gauges (MIG)}


The Granville Phillips Micro Ion Gauge No. 355001 is about $10 \mathrm{~cm}$ long with a maximum diameter of $7.3 \mathrm{~cm}$. These dimensions are sufficiently small that it allows a magnetically shielded gauge to be installed on the NSTX outer vacuum vessel, in a high conductance configuration for fast pressure measurements during plasma operation. These have proved especially valuable for routine NSTX operations. Very successful operation of two of these gauges has motivated us to install a total of five of these gauges at different toroidal and poloidal locations. As shown in Figure 2, two of the shielded fast Micro Ion Gauges (MIG) installed two years ago have maintained their calibration. The shielding is effective for the full $0.6 \mathrm{~T}$ on axis field capability of NSTX. These gauges, however, become contaminated if they are not isolated from the vessel during high temperature $\left(300^{\circ} \mathrm{C}\right)$ bake-out. This is probably because of the deposition of hydrocarbons on the gauge surfaces as the cold gauge (with respect to the high temperature vessel surfaces) essentially acts as a pump collecting impurities. Contamination is exhibited by signal dropouts, which result is an overall noisy signal. While degassing the gauge is able to restore most of its capability, the gauge never fully recovers to its original specifications. We have not investigated the possibility of keeping the gauge hot during bake-out. However, they do not seem to be affected by boronization and He glow discharge cleaning. On NSTX these gauges have a maximum range of 4mTorr, however if desired they can be easily operated at pressures in excess of $10 \mathrm{mTorr}$.

\section{The In-Vessel Neutral Pressure gauge (INP)}

The advantage of the micro ion gauge is that it provides accurate neutral pressure measurements during plasma operations, but it is limited by the magnitude of the magnetic field that can be effectively shielded. In addition this gauge cannot be installed inside the vessel. While the Penning gauge can be installed inside the vessel, it is less accurate than the ion gauge, but it can tolerate considerably high values of the magnetic field. In order to improve pressure measurements inside the vessel, we have investigated both in laboratory setups as well as testing gauges on NSTX, the possibility of using an unshielded ion gauge. The In-Vessel Neutral Pressure gauge (INP) is a gauge configuration we have successfully used in NSTX during plasma discharges. 
The gauge is designed so as to be insensitive to the magnetic field direction along the toroidal and poloidal directions in NSTX. The filament is the central tungsten wire, which is surrounded by a stainless steel spiral wire, which acts as the grid. The outermost spiral is the collector. The filament is tungsten wire .007" x 1 "long. The collector spiral is about $7 / 8$ " long.

Several different sizes were tested. The design that has worked during plasma operations in NSTX is shown in Figure 3. To increase filament lifetime, the filament is heated using an alternating current source. The filament is energized just before a shot cycle and turned off immediately following the shot. The gauge is driven at moderate emission current levels of about $2 \mathrm{~mA}$. This is similar to the levels of emission current used for the micro ion gauge, which varies from 0.5 to $2 \mathrm{~mA}$ depending on the maximum pressure range that is desired.

\section{Behavior of gauges in a vacuum magnetic field and during plasma operations}

The time response of the different pressure gauges when subjected to a step function rise in vacuum vessel pressure in shown in Figure 4. Shown from top to bottom are the MIG gauges E, C-Top, C-Midplane and L. The Penning gauges K-Top and G-Bottom. The InVessel Neutral Pressure (INP) gauge in Bay C-Top. The labels A to L correspond to the twelve different bays in NSTX. The pumping duct is located on Bay L. The MIG-E is the fastest responding gauge. The other MIG's respond slower because of conductance limitations.

The data was collected when gas was injected into a $0.45 \mathrm{~T}$ toroidal field on axis vacuum discharge. The higher noise levels in the INP gauge may be related to the fact that this gauge is located inside the vessel, so it cannot be isolated during machine bake-out and so it is subject to some level of gauge contamination. This is an inherent difficulty with any gauge that needs to be installed inside the machine. 
In general the response time of the micro ion gauges ranges from $5 \mathrm{~ms}$ (for the Bay-E gauge) to about $20 \mathrm{~ms}$ for the bay-L gauge. The Penning and INP gauges have an effective response time of about $30 \mathrm{~ms}$.

Figure 5 shows the neutral pressure response during plasma operations at $0.45 \mathrm{~T}$. Shown from top to bottom are the plasma current, the $\mathrm{H}$-alpha signal, and signals from the different neutral pressure gauges. This is a lower single null discharge fueled by both the NSTX center-stack gas injection and gas injection from the outer vessel region. The center stack gas injection is clearly observed by the Bay-E MIG at about $80 \mathrm{~ms}$.

In general, the time response of the Bay-C Top INP gauge is similar to that of the Bay-C top MIG, but these are located in different regions. The MIG is mounted on an external port, while the INP is located directly behind a divertor plate in an area that is under consideration for a divertor cryo pump installation. The MIG-L is located on the pumping duct, therefore sees lower pressure than the other gauges. The Lower divertor penning gauge is located in a region that sees no plasma flows during this type of operation, therefore it sees the lowest pressure of all these gauges during lower single null operation.

\section{Conclusions}

Several fast neutral pressure gauges are routinely used in NSTX. These are used to measure the edge and divertor pressure during inductive and coaxial helicity injected (CHI) plasma operations and to provide input to transport codes such as TRANSP and DEGAS-2. Modified, PDX-type Penning gauges have been very reliable and have required no maintenance for over two years. They also seem to be the most resilient as far as gauge contamination is concerned when subjected to high temperature machine bakeout. The Micro Ion gauges provide the most accurate pressure measurements on a fast time scale. These require to be isolated from the machine during high temperature bakeout but are not affected by boronization and HeGDC. Successful initial neutral pressure measurements have been made using a new design In-Vessel Neutral Pressure gauge 
(INP gauge). This is an unshielded ion-gauge that is insensitive toroidal and poloidal magnetic fields.

\section{Acknowledgement:}

DOE contract numbers DE-AC02-76CH03073, DE-AC05-00R22725, supports this work.

\section{References}

[1] M. Ono et al., Nucl. Fusion 40, 557 (2000)

[2] R. Raman et al, Nucl. Fusion 41, 1081 (2001)

[3] G. Haas et al, J. Nucl. Mater. 121, 151 (1984)

[4] H.F. Dylla, J. Vac. Sci. Technol, 20,1119 (1982)

[5] R. Raman et al., Rev. Sci. Instrum. 74, 1900 (2003)

Figures captions

Figure 1: (a) The NSTX Penning gauge, (b) Pressure calibration curves from 2002 and a recent calibration from 2004. No maintenance work has been performed on these gauges during the past two years.

Figure 2: The Micro Ion Gauges retain their calibration over extended periods. Different gauges when operated at the same emission current setting exhibit the same calibration factor making it easy to replace damaged gauges, without having to recalibrate. The small physical size of these gauges allows them to be easily shielded from external magnetic fields.

Figure 3: The In-Vessel Neutral Pressure gauge (INP).

Figure 4: Time response of the different pressure gauges when subjected to a step function rise in vacuum vessel pressure.

Figure 5: Neutral pressure response during plasma operations at 0.45T. 
Figure 1
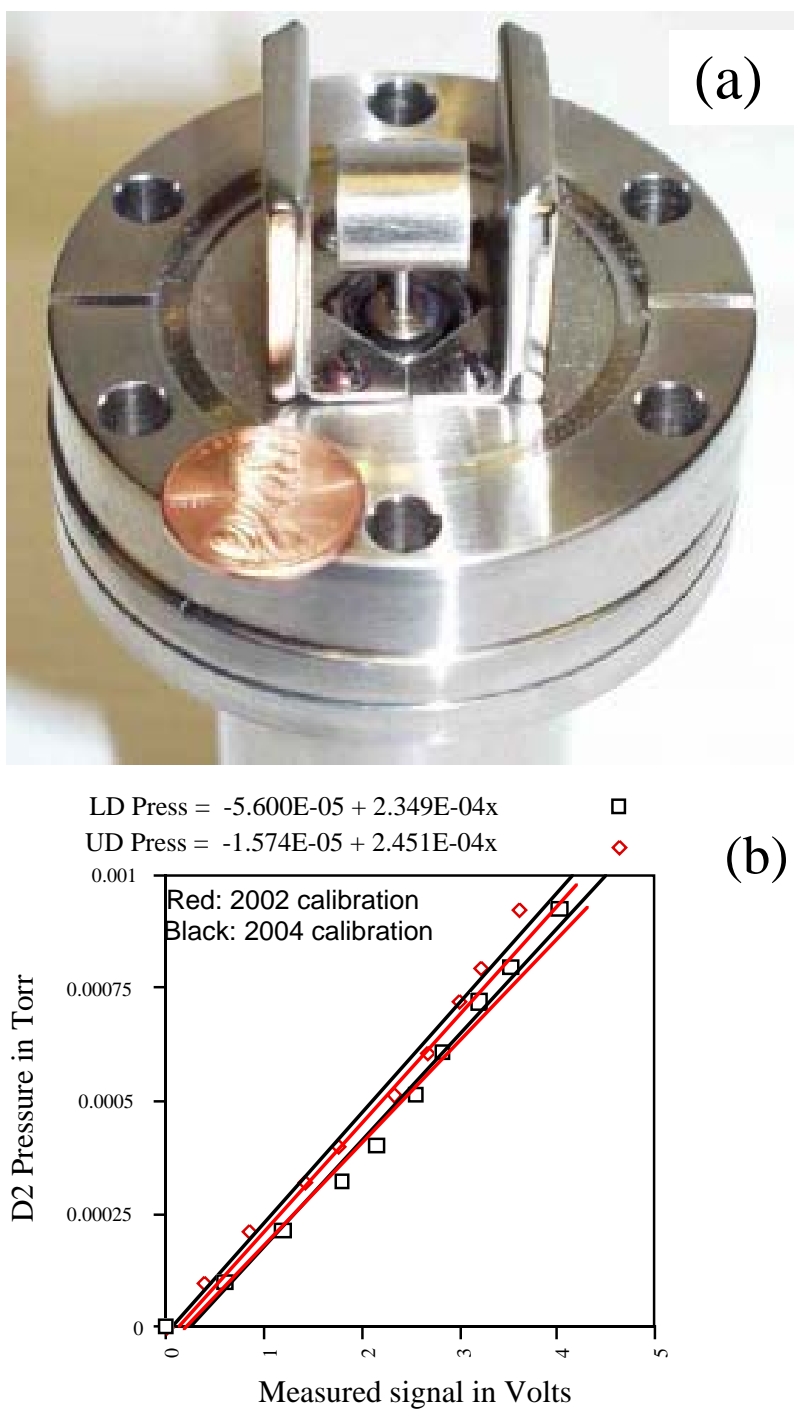

(b) 
Figure 2

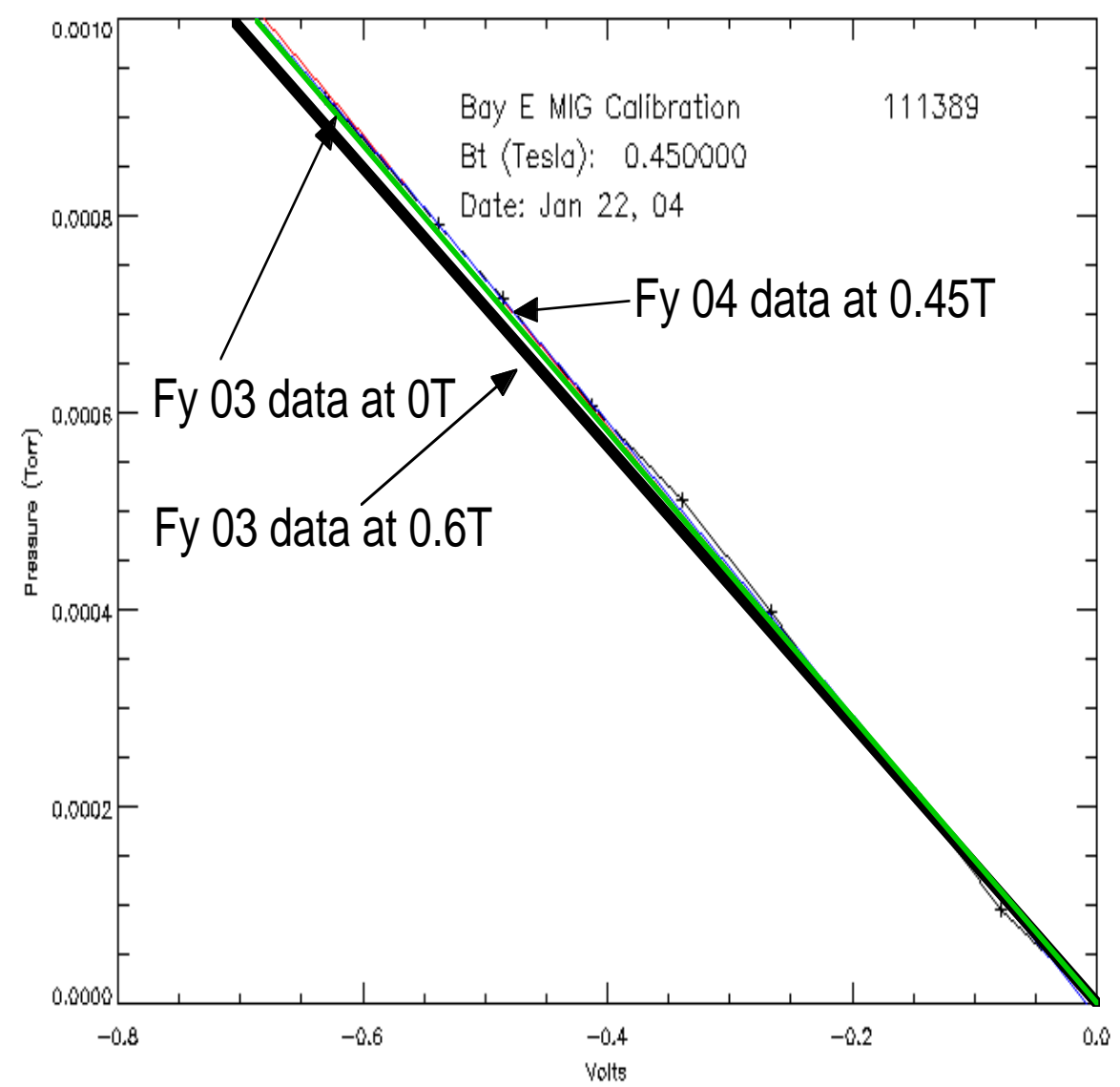


Figure 3

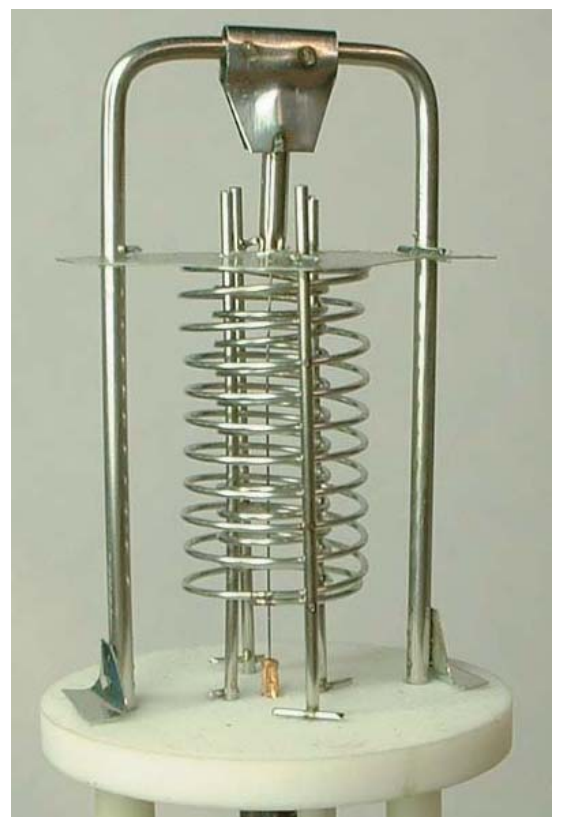


Figure 4

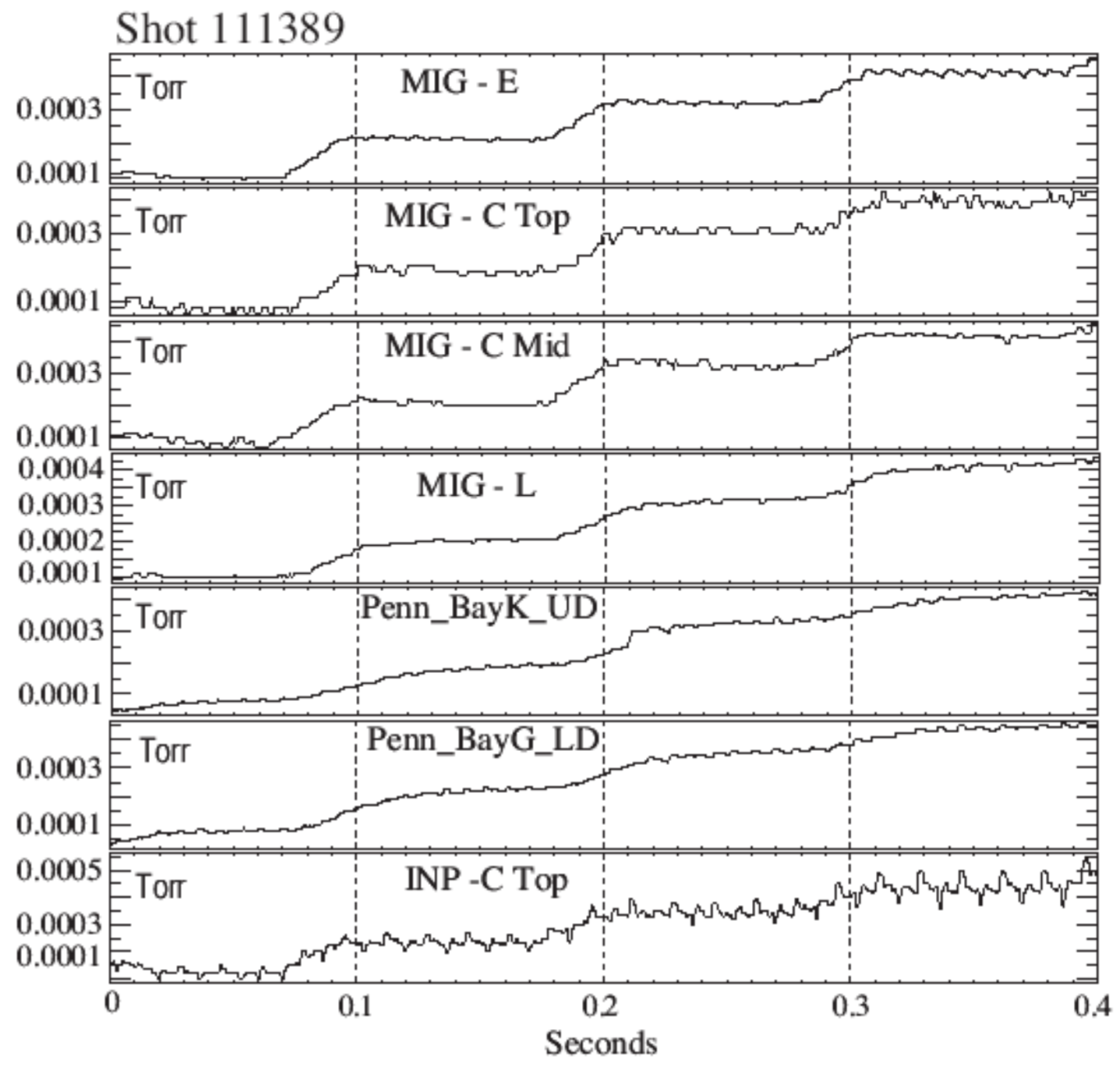


Figure 5

Shot 112118
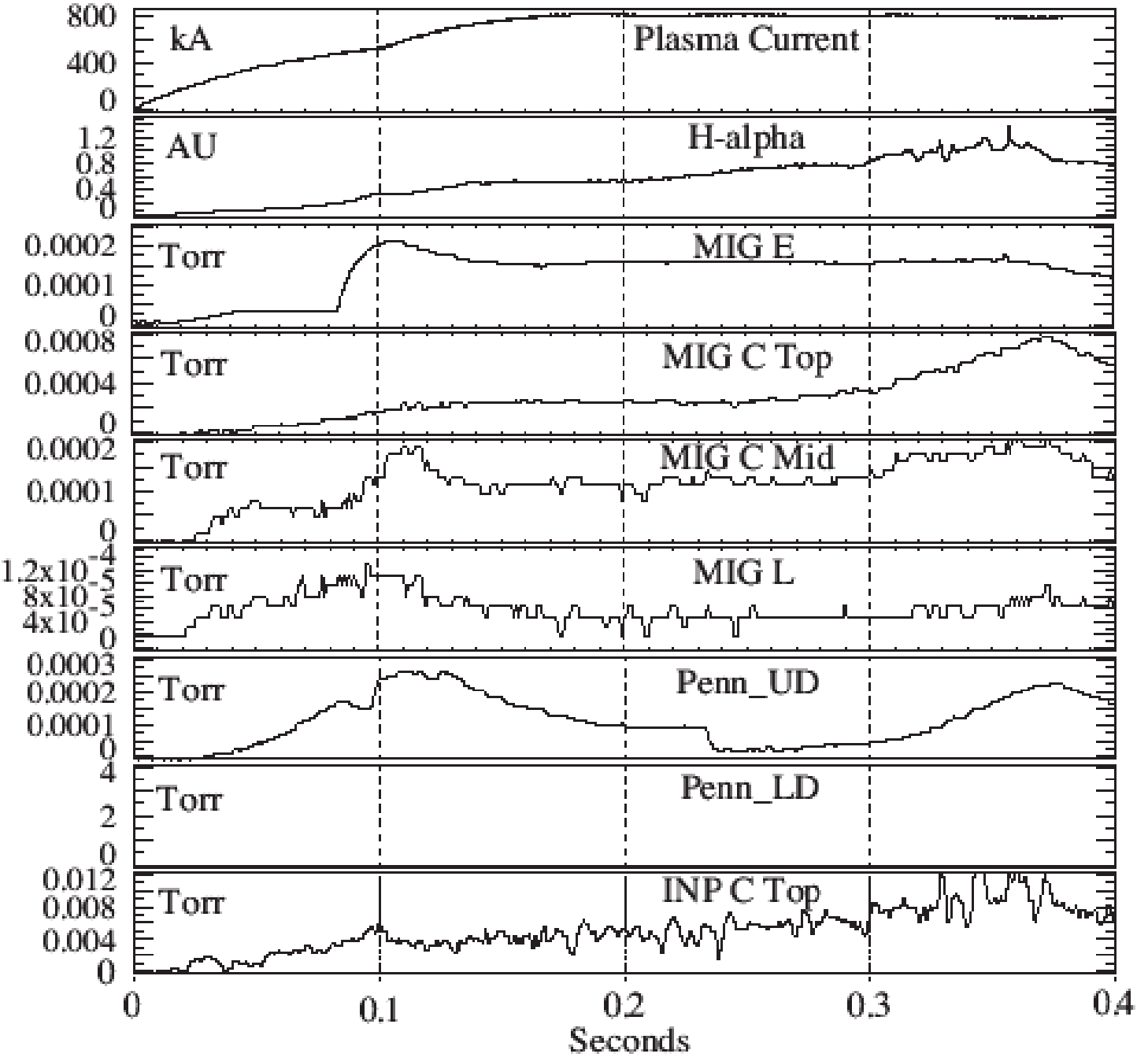


\section{External Distribution}

Plasma Research Laboratory, Australian National University, Australia

Professor I.R. Jones, Flinders University, Australia

Professor João Canalle, Instituto de Fisica DEQ/IF - UERJ, Brazil

Mr. Gerson O. Ludwig, Instituto Nacional de Pesquisas, Brazil

Dr. P.H. Sakanaka, Instituto Fisica, Brazil

The Librarian, Culham Laboratory, England

Mrs. S.A. Hutchinson, JET Library, England

Professor M.N. Bussac, Ecole Polytechnique, France

Librarian, Max-Planck-Institut für Plasmaphysik, Germany

Jolan Moldvai, Reports Library, Hungarian Academy of Sciences, Central Research Institute for Physics, Hungary

Dr. P. Kaw, Institute for Plasma Research, India

Ms. P.J. Pathak, Librarian, Institute for Plasma Research, India

Ms. Clelia De Palo, Associazione EURATOM-ENEA, Italy

Dr. G. Grosso, Instituto di Fisica del Plasma, Italy

Librarian, Naka Fusion Research Establishment, JAERI, Japan

Library, Laboratory for Complex Energy Processes, Institute for Advanced Study, Kyoto University, Japan

Research Information Center, National Institute for Fusion Science, Japan

Dr. O. Mitarai, Kyushu Tokai University, Japan

Dr. Jiangang Li, Institute of Plasma Physics, Chinese Academy of Sciences, People's Republic of China

Professor Yuping Huo, School of Physical Science and Technology, People's Republic of China

Library, Academia Sinica, Institute of Plasma Physics, People's Republic of China

Librarian, Institute of Physics, Chinese Academy of Sciences, People's Republic of China

Dr. S. Mirnov, TRINITI, Troitsk, Russian Federation, Russia

Dr. V.S. Strelkov, Kurchatov Institute, Russian Federation, Russia

Professor Peter Lukac, Katedra Fyziky Plazmy MFF UK, Mlynska dolina F-2, Komenskeho Univerzita, SK-842 15 Bratislava, Slovakia

Dr. G.S. Lee, Korea Basic Science Institute, South Korea

Institute for Plasma Research, University of Maryland, USA

Librarian, Fusion Energy Division, Oak Ridge National Laboratory, USA

Librarian, Institute of Fusion Studies, University of Texas, USA

Librarian, Magnetic Fusion Program, Lawrence Livermore National Laboratory, USA

Library, General Atomics, USA

Plasma Physics Group, Fusion Energy Research Program, University of California at San Diego, USA

Plasma Physics Library, Columbia University, USA

Alkesh Punjabi, Center for Fusion Research and Training, Hampton University, USA

Dr. W.M. Stacey, Fusion Research Center, Georgia Institute of Technology, USA

Dr. John Willis, U.S. Department of Energy, Office of Fusion Energy Sciences, USA

Mr. Paul H. Wright, Indianapolis, Indiana, USA 
The Princeton Plasma Physics Laboratory is operated by Princeton University under contract with the U.S. Department of Energy.

\author{
Information Services \\ Princeton Plasma Physics Laboratory \\ P.O. Box 451 \\ Princeton, NJ 08543
}

Phone: 609-243-2750

Fax: 609-243-2751

e-mail: pppl_info@pppl.gov

Internet Address: http://www.pppl.gov 